\title{
A Study on the Major Satisfaction and Career Identity among College Students
}

\author{
Miok Kim ${ }^{1}$ \\ ${ }^{1}$ Professor, Nursing Department, TongMyung University, South Korea, citycoco@ hanmail.net
}

\begin{abstract}
This study investigates the major satisfaction and career identity among college students, identify the relationship between these two variables, and determin the difference of major satisfaction and career identity according to the general characteristics. A survey was conducted on 183 male and female college students attending a university in Busan from April 1 to April 15, 2020. The collected data were analyzed by frequency and percentage, mean and standard deviation, independent T-test, oneway ANOVA, and Pearson correlation analysis. As a result, the average major satisfaction and career identity among college students was 3.73 points and 3.16 points on average. As a result of analyzing the difference between major satisfaction and career identity according to general characteristics, in the case of major satisfaction, there was a significant difference in grade, major, practice repair, career education help level, and department selection motivation. In the case of career identity, there was a significant difference in major, practice experience, career education help level, reason for satisfaction of major and department selection motivation. As a result of the correlation analysis of the two variables, career identity showed a statisticallly significant positive correlation with major satisfaction.. These results indicated that programs for improving major satisfaction and career identity in colleges should particulary emphasize subject satisfaction and careew identity emotion, and should be differentiated according to grades and majors.
\end{abstract}

Keywords : Major Satisfaction, Career Identity, Practice Experience, College Students

\section{Introduction}

College student period is an important stage of career development transitioning students from school work to real work scenario by realistically specifying and preparing one's career path in the process of realizing life[1]. In a survey on college students conducted by the Korea Vocational Competency Development Institute (2014), career issues were the biggest problem. Recently, attempts were made to help students in their environmental conditions by expanding various scholarship systems, operating undergraduate programs, and expanding convenience facilities, but the actual use of these systems depends entirely on the will of the university students and mainly depends on the psychological characteristics of the individuals[2]. It can be said that the most influencing thing on the life satisfaction of college students is academic satisfaction, which expresses the enjoyment of all the roles and experiences played by students. The satisfaction of a college student's major is the same as job satisfaction of a professional, and is the product of a judgment process that evaluates the subject of their current major by comparing it with the criteria for a career or job set by an individual[3].

Most of the major selection is the result of a combination of factors. In other words, in addition to personal factors such as gender, the results of external factors such as the influence of parents or teachers

Received: December 15, 2020; $1^{\text {st }}$ Review Result: January 27, 2021; $2^{\text {nd }}$ Review Result: March 15, 2021 Accepted: April 30, 2021 
and differences in social class can also influence the selection of a major. The significance of college students' satisfaction towards their chosen major is important not only to their college life but also to the direction of their future career[4]. Since it is formed by the interaction between the individual characteristics and the environment surrounding the major to which the student belongs, when a good understanding of the perspective towards real work scenario is more important in career attitude[5].

Most college students choose their major depending on whether their aptitude matches their career after graduation, but many students tend to choose a major in a state of lack of understanding and awareness of the major, resulting in decreased adaptability to the major and low major satisfaction[6].

College students continue to interact with their surroundings to form a sense of career identity. However, one of the things that occupies the greatest weight in the process of forming college students' career identity is the satisfaction with their major. This is because college life itself is organized by major field, and majors are usually directly connected to future career paths. In addition, the degree of satisfaction with the major is not only a matter of individual level, but is influenced by the external environment, so the formation of self-identity and career choice are not independent concepts, but are processes that must be done simultaneously[7]. Career identity is an accurate understanding of each individual's unique characteristics and recognition of what occupations can be realized and to have a clear and stable image of one's goals, interests, and abilities. It affects each individual's career decision, and has a great influence on professional identity and career decision behavior[8]. Holland said that a person who currently has a clear prize for his or her goals, interests, personality, and talents is a person with a developed sense of career identity, on the other hand, those who have difficulty in making career decisions because they do not know their own characteristics or talents have a low sense of career identity. It has a positive effect on college students' career development and self-identity development[9]. College students fall under the latter half of adolescence and have to accomplish the whole-personal development task of achieving self-identity, self-image, autonomy and psychological independence. So, the formation of self-identity and career choice are not independent concepts, but are a process that must be done simultaneously. Successful career choice and career decision can be made only when a sense of career identity, which represents the degree of confidence in career decision and direction setting for a career designed by an individual[10]. College students fall under the latter half of adolescence and have to accomplish the whole-personal development task of achieving self-identity, self-image, autonomy and psychological independence. So, the formation of self-identity and career choice are not independent concepts, but are a process that must be done simultaneously. Successful career choice and career decision can be made only when a sense of career identity, which represents the degree of confidence in career decision and direction setting for a career designed by an individual[10]. College student period is the time to establish a sense of self-identity through training and education, and to choose suitable career. They have a clear understanding of own personality, tastes, values, abilities and interests, and outlook on humanity, worldview, and future so that they can decide on themselves and the career path to choose. They must be able to perform their own functions of integrating their ideals, behaviors, and social roles.

Therefore, it is necessary to examine the degree of major satisfaction and career identity, and to investigate the factors that affect career identity by testing the difference between the two research variables according to general characteristics. It aims to improve college students' ability to adapt to college life and provide basic data for career guidance.

The specific research objectives are as follows.

1) Identify the general characteristics of the subjects, and investigate the degree of their major satisfaction and career identity

2) Identify the difference in major satisfaction and career identity according to the general characteristics of the subjects

3) Identify the correlation between major satisfaction and career identity 


\section{Method}

\subsection{Study Design}

This is a descriptive research design conducted to investigate the relationship between satisfaction towards chosen major and career identity for college students in the process of employment and career choice, and to identify the factors that affect career identity by identifying differences according to general characteristics of college students .

\subsection{Subjects}

The subjects of this study were 183 male and female college students enrolled in a four-year university located in Busan, They voluntarily agreed upon the explanation of the purpose and method of the study.

\subsection{Instruments}

\subsubsection{Major Satisfaction}

In order to measure the subjects' satisfaction towards their chosen major satisfaction, this study used Lee's major satisfaction tool developed by Ha (2000). This tool consists of a total of 18 questions, consisting of four sub-areas: general satisfaction (6 questions), cognitive satisfaction (6 questions 0 , subject satisfaction (3 questions), and relationship satisfaction between professors and students (3 questions).

The measurement criterion uses a five-point Likert scale with one point as 'not at all' to five points as 'very much'. The higher the score, the higher the degree of satisfaction towards their major. As for the reliability of the tool, the Cronbach $\alpha$ value in Lee's study (2004) was .90, and the Cronbach $\alpha$ value in this study was .93 .

[Table 1] Item Composition and Reliability of Instrument

\begin{tabular}{cccc}
\hline Instrument & Question number & Number of question & Reliability \\
\hline Major satisfaction & & 18 & .93 \\
\hline General satisfaction & $1,2,3,4,5,6$ & 6 & .91 \\
\hline Recognition satisfaction & $7,8,9,10,11,12$ & 6 & .90 \\
\hline subject satisfaction & $13,14,15$ & 3 & .81 \\
\hline Relationship satisfaction & $16,17,18$ & 3 & .85 \\
\hline
\end{tabular}

\subsubsection{Career Identity}

To measure career identity, the career identity scale for college students developed by Kim Shin-jeong and Kim Seong-hee (2012) was used. This scale has a total of 23 items, including 8 items on career identity, 7 items on career identity perception, and 8 items on career identity behavior. The response style is based on the Likert 5-point scale, and the higher the score, the higher the sense of career identity. The Cronhbach's $\alpha$ value of the career identity scale for college students developed by Shin-Jung Kim and Seong-Hee Shim (2012) was .95 and in this study was .91. 
[Table 2] Item Composition and Reliability of Instrument

\begin{tabular}{cccc}
\hline Instrument & Question number & Number of question & Reliability \\
\hline Career identity & & 23 & .91 \\
\hline Career identity emotion & $1 \sim 8$ & 8 & .93 \\
\hline Career identity recognition & $9 \sim 15$ & 7 & .86 \\
\hline Career identity behavior & $16 \sim 23$ & 8 & .81 \\
\hline
\end{tabular}

\subsection{Data Collection and Analysis}

\subsubsection{Data Collection}

The data collection period took place from April 01, 2020 to April 15, 2020 With the help of the university department. The purpose of the study was directly explained to the study subjects, and the personal information entered in the questionnaire was guaranteed to be confidential, and the results of the questionnaire were not used for purposes other than the study. The decision to participate in the study was voluntary, and the subjects who indicated their intention to participate in the study were asked to fill out a written consent form and questionnaire and collected it on the spot. The data collection period was from April 01 to April 15, 2020, and a total of 190 copies were used for the final analysis, excluding 7 copies with unsuccessful responses among a total of 183 cases.

\subsubsection{Data Analysis Method}

The collected data were analyzed using IBM SPSS Statistics version 25, and the general characteristics of the study subjects were analyzed by frequency and percentage, and the degree of major satisfaction and career identity were by means and standard deviation. In order to find out the difference in major satisfaction and career identity according to general characteristics, t-test and F-test by oneway ANOVA were conducted. Sheffe test was used for post verification. Pearson's Correlation Analysis was conducted to find out the correlation between major satisfaction and career identity

\section{Results}

\subsection{General Characteristics}

In terms of grades, '4th grade' is the largest with 80 students (43.7\%), '3rd grade' with 46 students (25.1\%), '2nd grade' with 34 students (18.6\%), and '1st grade' with 23 students (12.6\%). The majors were'medicine and health' with 103 students (53.6\%), 'engineering' with 35 students $(19.1 \%)$, 'humanities and social sciences' with 20 students (10.9\%), arts and physical education with 13 students (7.1\%), and the other majors with 12 students (4.8\%). As for the field experience, 92 people (50.3\%) said 'have' and $90(49.2 \%)$ said 'nothing'. When asked about compensation for on-site training, 67 (36.6\%) answered 'No' and $25(13.7 \%)$ answered 'Yes'. In the field training period, ' 1 month to 3 months' is the most with 55 people (30.1\%), ' 4 months to 6 months' with 21 people (11.5\%), '1 year or more' with 8 people (4.4\%), '7 months to 9 months' with 6 people (3.3\%), and '10 to 12 months' with 1 respondent $(0.5 \%)$. When asked whether career education was helpful, 98 people $(53.6 \%)$ answered 'somewhat helpful', 48 (26.2\%) answered 'nearly no', 25 (13.7\%) answered 'very helpful', and 11 (6.0\%) 
showed 'not helpful'. As for the 'reasons for satisfaction with major,' 82 people (44.8\%) answered that 'employment is advantageous', 46 (25.1\%) answered 'This is the major they wanted', $26(14.2 \%)$ answered 'suitable for aptitude or talent, 21 (11.5\%) answered 'Is of interest', and 6 (3.3\%) showed 'rewarding pride attachment'. In terms of motiviation on major selection, 'Aptitude and Hobbies' was the most common with 72 (39.3\%), 'employment rate' was 59 (32.2\%), 'recommendation' was 26 (14.2\%), and 'Aptitudes' was 24(13.1\%). As for the factors to consider when choosing a job, 'income pay' was the most with 59 people (32.2\%), 48 (26.2\%) for 'stability', 46 (25.1\%) for 'aptitude interest', 12 for (6.6\%) 'promotion opportunity', 7 (3.8\%) for 'Job Content', 7 (3.8\%) for 'Autonomous Creativity', 3 (1.6\%) for 'Social Volunteer Contribution'. In the terms of socioeconomic class, 'middle' was the most with 90 (49.2\%) responses, 'severe' with 44 (24.0\%), 'middle and low' with 41 (22.4\%), and 'low' with 7 (3.8\%).

[Table 3] General Characteristics $(\mathrm{N}=183)$

\begin{tabular}{|c|c|c|c|}
\hline Characteristics & Category & $\mathrm{n}$ & $\%$ \\
\hline \multirow{2}{*}{ Sex } & Male & 33 & 18.0 \\
\hline & Female & 150 & 82.0 \\
\hline \multirow{4}{*}{ Grade } & 1 st grade & 23 & 12.6 \\
\hline & 2 nd grade & 34 & 18.6 \\
\hline & 3 rd grade & 46 & 25.1 \\
\hline & 4 rd grade & 80 & 43.7 \\
\hline \multirow{5}{*}{ Major } & Humanities and social science & 20 & 10.9 \\
\hline & Engineering & 35 & 19.1 \\
\hline & Health & 103 & 56.3 \\
\hline & Arts and physical & 13 & 7.1 \\
\hline & and others & 12 & 6.6 \\
\hline \multirow{2}{*}{ Practice experience } & Yes & 92 & 50.3 \\
\hline & No & 91 & 49.2 \\
\hline \multirow{2}{*}{ Practice repaire } & Yes & 25 & 13.7 \\
\hline & No & 67 & 36.6 \\
\hline \multirow{4}{*}{ Practice period } & $1 \sim 3$ mon. & 55 & 30.1 \\
\hline & $4 \sim 6$ mon. & 21 & 11.5 \\
\hline & $7 \sim 10$ mon. & 6 & 3.3 \\
\hline & Over 1 year & 9 & 4.4 \\
\hline \multirow{4}{*}{ Career education help level } & Not helpful & 11 & 6.0 \\
\hline & Nearly not helpful & 48 & 26.2 \\
\hline & Little helpful & 98 & 53.6 \\
\hline & Very helpful & 25 & 13.7 \\
\hline Reason for major satisfaction & Desired major & 46 & 25.1 \\
\hline
\end{tabular}




\begin{tabular}{cccc}
\hline & Aptitude & 26 & 14.2 \\
Interest & 21 & 11.5 & 44.8 \\
Employment & 82 & 3.3 \\
\hline \multirow{2}{*}{ Major selection motivation } & Pride & 6 & 13.1 \\
& Aptitude & 24 & 39.3 \\
& Employment & 72 & 32.2 \\
\hline \multirow{2}{*}{ Job selection consideration } & Advice & 59 & 14.2 \\
\hline Stability & 26 & 26.2 \\
& Aptitude & 48 & 25.1 \\
& Social service & 46 & 1.6 \\
& Job description & 3 & 3.8 \\
& Autonomy & 7 & 3.8 \\
& Repaire & 7 & 32.2
\end{tabular}

\subsection{Dgree of the Major Satisfaction and Career Identity}

The subject's degree of satisfaction and career identity was $3.73 \pm .72$ points and $3.16 \pm .40$ points, respectively. In the sub-area of major satisfaction, recognition satisfaction was the highest at 4.00 and subject satisfaction was the lowest at 3.42. In the sub-area of career identity, career identity recognition was the highest with 3.92points and career identity emotion was the lowest at 2.66 points.

[Table 4 ] Mean Score of the Major Satisfaction and Career Identity

\begin{tabular}{ccc}
\hline & $\mathrm{M} \pm \mathrm{SD}$ & M in- MAX \\
\hline Major satisfaction & $3.73 \pm .72$ & $1-5$ \\
\hline General satisfaction & $3.61 \pm .85$ & $1-5$ \\
\hline Recognition satisfaction & $4.00 \pm .87$ & $1-5$ \\
\hline Subject satisfaction & $3.42 \pm .91$ & $1-5$ \\
\hline Relationship satisfaction & $3.72 \pm .91$ & $1-5$ \\
\hline Career identity & $3.16 \pm .40$ & $1-5$ \\
\hline Career identity emotion & $2.61 \pm .99$ & $1-5$ \\
\hline Career identity recognition & $3.92 \pm .70$ & $1-5$ \\
\hline Career identity behavior & $3.06 \pm .72$ & $1-5$ \\
\hline
\end{tabular}




\subsection{Difference of the Major Satisfaction and Career Identity according to General Characteristics}

[Table 3] shows the difference between major satisfaction and career identity according to general characteristics. There were no significant differences in gender, field training period, factors to consider when choosing a job, and socioeconomic status in both major satisfaction and career identity. However, in the case of major, degree of help in career education, and motive for selecting a department, there were statistically significant differences in major satisfaction and career identity.

Grade $(\mathrm{F}=2.262, \mathrm{p}=.05)$, major $(\mathrm{f}=4.700, \mathrm{p}(<.001)$, practice repair $(\mathrm{F}=-2.667, \mathrm{p}=.009)$, career education help level $(\mathrm{F}=13.514, \mathrm{p}<.001)$, and major selection motivation $(\mathrm{F}=5.426, \mathrm{p}<.001)$ showed statistically significant differences in major satisfaction, and the 3rd graders showed higher major satisfaction than the 1st graders. The group who answered that the medical and health majors were higher than those of other majors and that career education was helpful compared to the other groups.In addition, it was found that the group who selected aptitude or employment rate as the motive for selecting a department had higher major satisfaction than the group selected by score.

In the case of career identity, major $(\mathrm{F}=2.788, \mathrm{p}=.028)$, practice experience $(\mathrm{F}=1.153, \mathrm{p}=.025)$, career education help level $(\mathrm{F}=6.714, \mathrm{p}<.001)$, major satisfaction reason $(\mathrm{F}=3.860, \mathrm{p}=.005)$ and major selection motivation $(\mathrm{F}=6.406, \mathrm{p}<.001)$ showed a significant difference. Specifically, the arts and sports disciplines had higher career identity than other majors.

The group who answered that they had experience in the field and that career education was helpful had higher career identity than the other groups, and the group who answered that the reason for satisfaction with the major was the desired major was statistically significantly higher in career identity than the other groups.

[Table5] Difference of the Major Satisfaction and Career Identity according to General Characteristics

\begin{tabular}{|c|c|c|c|c|c|}
\hline \multirow{2}{*}{ Characteristics } & \multirow{2}{*}{ Category } & \multicolumn{2}{|c|}{ Major satisfaction } & \multicolumn{2}{|c|}{ Career identity } \\
\hline & & $\mathrm{M} \pm \mathrm{SD}$ & t or $F(p)$ & $\mathrm{M} \pm \mathrm{SD}$ & t or $F(p)$ \\
\hline \multirow{2}{*}{ Sex } & Male & $3.62 \pm .76$ & \multirow{2}{*}{$-.961(.723)$} & $3.47 \pm .64$ & \multirow{2}{*}{$-.621(.681)$} \\
\hline & Female & $3.75 \pm .71$ & & $3.55 \pm . .64$ & \\
\hline \multirow{4}{*}{ Grade } & 1 st grade & $3.94 \pm .50$ & \multirow{4}{*}{$2.262(.050)$} & $3.25 \pm .26$ & \multirow{4}{*}{$1.432(.235)$} \\
\hline & 2 nd grade & $3.89 \pm .68$ & & $3.19 \pm .34$ & \\
\hline & 3 rd grade & $3.51 \pm .83$ & & $3.06 \pm .50$ & \\
\hline & 4 rd grade & $3.71 \pm .70$ & & $3.18 \pm .39$ & \\
\hline \multirow{5}{*}{ Major } & $\begin{array}{c}\text { Humanities and social } \\
\text { science }\end{array}$ & $3.40 \pm .95$ & \multirow{5}{*}{$4.700(<.001)$} & $3.29 \pm .74$ & \multirow{5}{*}{$2.788(.028)$} \\
\hline & Engineering & $3.46 \pm .11$ & & $3.43 \pm .43$ & \\
\hline & Health & $3.93 \pm .05$ & & $3.59 \pm .65$ & \\
\hline & Arts and physical & $3.75 \pm .63$ & & $3.94 \pm .65$ & \\
\hline & and others & $3.27 \pm .87$ & & $3.34 \pm .69$ & \\
\hline Practice experience & Yes & $3.75 \pm .67$ & $.344(.731)$ & $3.59 \pm .58$ & $1.153(.025)$ \\
\hline
\end{tabular}




\begin{tabular}{|c|c|c|c|c|c|}
\hline & No & $3.71 \pm .76$ & & $3.48 \pm .71$ & \\
\hline \multirow{2}{*}{ Practice repaire } & Yes & $3.45 \pm .74$ & \multirow{2}{*}{$-2.667(.009)$} & $3.64 \pm .59$ & $.467(.642)$ \\
\hline & No & $3.86 \pm .62$ & & $3.58 \pm .58$ & \\
\hline \multirow{4}{*}{ Practice period } & 1 3 mon. & $3.72 \pm .68$ & \multirow{4}{*}{$.125(.973)$} & $3.16 \pm .44$ & \multirow{4}{*}{$.290(.884)$} \\
\hline & $4 \sim 6$ mon. & $3.78 \pm .72$ & & $3.16 \pm .41$ & \\
\hline & $7 \sim 10$ mon. & $3.83 \pm .90$ & & $3.13 \pm .30$ & \\
\hline & Over 1 year & $3.81 \pm .46$ & & $3.20 \pm .42$ & \\
\hline \multirow{4}{*}{$\begin{array}{l}\text { Career education help } \\
\text { level }\end{array}$} & Not helpful & $3.00 \pm .91$ & \multirow{4}{*}{$\begin{array}{c}13.514(<.001) \\
\mathrm{a}, \mathrm{b}<\mathrm{c}, \mathrm{d}\end{array}$} & $3.16 \pm .65$ & \multirow{4}{*}{$\begin{array}{l}6.714(<.001) \\
\quad \text { a,b,c }<\mathrm{d}\end{array}$} \\
\hline & Nearly not helpful & $3.43 \pm .72$ & & $3.38 \pm .54$ & \\
\hline & Little helpful & $3.81 \pm .57$ & & $3.52 \pm .60$ & \\
\hline & Very helpful & $4.25 \pm .66$ & & $3.98 \pm .72$ & \\
\hline \multirow{5}{*}{$\begin{array}{l}\text { Reason for major } \\
\text { satisfaction }\end{array}$} & Desired major & $3.76 \pm .86$ & \multirow{5}{*}{$1.731(.145)$} & $3.74 \pm .74$ & \multirow{5}{*}{$\begin{array}{c}3.860(.005) \\
\quad \mathrm{a}>\mathrm{c}\end{array}$} \\
\hline & Aptitude & $3.94 \pm .67$ & & $3.75 \pm .63$ & \\
\hline & Interest & $3.43 \pm .70$ & & $3.23 \pm .63$ & \\
\hline & Employment & $3.70 \pm .62$ & & $3.42 \pm .53$ & \\
\hline & Pride & $3.95 \pm .33$ & & $3.76 \pm .42$ & \\
\hline \multirow{4}{*}{$\begin{array}{l}\text { Major selection } \\
\text { motivation }\end{array}$} & Record & $3.21 \pm .84$ & \multirow{4}{*}{$\begin{array}{c}5.426(.001) \\
a<b, c, d\end{array}$} & $3.36 \pm .57$ & \multirow{4}{*}{$\begin{array}{c}6.406(<.001) \\
\quad b>c, d\end{array}$} \\
\hline & Aptitude & $3.83 \pm .65$ & & $3.77 \pm .64$ & \\
\hline & Employment & $3.74 \pm .63$ & & $3.40 \pm .52$ & \\
\hline & Advice & $3.88 \pm .75$ & & $3.31 \pm .71$ & \\
\hline \multirow{7}{*}{$\begin{array}{l}\text { Job selection } \\
\text { consideration }\end{array}$} & Stability & $3.95 \pm .62$ & \multirow{7}{*}{$1.735(.115)$} & $3.10 \pm .41$ & \multirow{7}{*}{$.551(.769)$} \\
\hline & Aptitude & $3.53 \pm .84$ & & $3.25 \pm .35$ & \\
\hline & Social service & $3.83 \pm .48$ & & $3.02 \pm .06$ & \\
\hline & Job description & $3.96 \pm .52$ & & $3.18 \pm .37$ & \\
\hline & Autonomy & $3.46 \pm .52$ & & $3.22 \pm .19$ & \\
\hline & Repaire & $3.70 \pm .69$ & & $3.10 \pm .44$ & \\
\hline & Promotion opportunity & $3.60 \pm .53$ & & $3.75 \pm .71$ & \\
\hline \multirow{4}{*}{ Economic state } & Middle to high & $3.82 \pm .69$ & \multirow{4}{*}{$1.505(.215)$} & $3.19 \pm .39$ & \multirow{4}{*}{$1.698(.169)$} \\
\hline & Middle & $3.73 \pm .67$ & & 3. $10 \pm .42$ & \\
\hline & Low to middle & $3.69 \pm .70$ & & $3.23 \pm .35$ & \\
\hline & Low & $3.19 \pm 1.10$ & & $3.34 \pm .29$ & \\
\hline
\end{tabular}

\subsection{Correlations between the major satisfaction and career identity}

[Table 4] shows the results of analyzing the correlation between major satisfaction and career identity. There was a statistically significant positive correlation between major satisfaction and career identity $(\mathrm{r}=.530, \mathrm{p}<.001)$. This means that the higher the degree of satisfaction with the major, the higher the sense of career identity. 
[Table 6] Correlations between the Major Satisfaction and Career Identity

\begin{tabular}{ccc}
\hline & Major satisfaction & Career identity \\
\hline \hline \multirow{2}{*}{ Major satisfaction } & 1 & \\
\cline { 2 - 3 } Career identity & $.530(<.001)$ & 1 \\
\hline
\end{tabular}

\section{Conclusion}

In this study, the satisfaction towards the chosen majors and the sense of career identity of the subjects in the process of employment and career selection were investigated, not only through the subjects' general characteristics but also based on various career-related characteristics, such as major, field experience, training remuneration, field training period, reasons, motives for choosing a department, and factors to consider when choosing a job.

To collect data, a questionnaire was distributed to 183 college students in the 1st, 2nd, 3rd, and 4th grades of a university in Busan who are in the course of employment and career selection.

One-way analysis of variance (ANOVA), Pearson's Correlation Analysis and Cronbach's Alpha was calculated for the reliability of the tool.

The subject's degree of major satisfaction was 3.73 points and 3.16 points, respectively. Among the sub-area of major satisfaction, subject satisfaction was the lowest with 3.42 points, among the sub-area of career identity, the career identity emotion was the lowest with 2.61 points.

As a result of analyzing the difference between major satisfaction and career identity according to the general characteristics, in the case of major satisfaction, major, practice repair , career education help level, and department selection motivation showed significant differences. The 3rd graders were more satisfied with their major than the 1st graders, the medical and health majors were higher than other majors, and the group who answered that career education was helpful was higher than the group that did not. The group who selected aptitude or employment as a motive for selecting a department showed higher major satisfaction than the group selected by grade.

In the case of career identity, major, field experience, career education help level, major satisfaction reason and subject selection motivation showed a significant difference. Specifically, the arts and sports field had a higher sense of career identity than other majors and the field experience. The group who answered that there was a lot of help and that the career education was helpful had a higher sense of career identity than the other groups, and the group who answered that the reason for satisfaction with the major was the desired major was significantly different than that of the interested group, indicating higher career identity.

There was a statistically significant positive correlation between major satisfaction and career identity . This means that the higher the degree of satisfaction with the major, the higher the sense of career identity. Integrating the above study results, major satisfaction and career identity are closely related, and it is necessary to develop differentiated programs for each grade and major in order to establish career identity for college students who are at an important point in career preparation.

Since this study was conducted with some local college students, it is difficult to generalize on the results, so it is recommended to select various targets for further studies. so it is recommended to select various targets in the further study. Also, it is recommended to develop an effective career guidance program for college students who need career guidance. 


\section{References}

[1] Y. O. Park, S. J. Park, J. Heo, A Study on the Effects of Employment Community Characteristics on Employment Community Commitment, Job Seeking Efficacy, and Job Seeking Behavior, Journal of Employment and Career, (2017), Vol.7, No.2, pp.103-124, DOI:10.35273/jec.2017.7.2.006

[2] I. S. Park, Y. J. Han, A Study on the Difference in Career Attitude Maturity, Career Identity, Stress Management, and Satisfaction for Major Classes of Nursing Students According to Demographic Characteristics, Journal of Employment and Career, (2017), Vol.7, No.1, pp.145-167, DOI:10.35273/jec.2017.7.1.007

[3] Y. S. Kang, S. K. Whang, Correlations of Self-esteem, Major satisfaction and Career motivation in College Nursing Students, Journal of the Korea Academia-Industrial cooperation Society, (2013), Vol.14, No.7, pp.3301-3309, https://doi.org/10.5762/KAIS.2013.14.7.3301

[4] I. S. Cho, H. J. Jeon, A Study to improve General Education Curriculum in University, Journal of Education and Culture, (2017), Vol.23, No.6, pp.133-155, http://dx.doi.org/10.24159/joec.2017.23.6.133

[5] Y. J. Han, J. H. Lee, A Study on Major Satisfaction and Career Maturity according to the Values of College Students Majoring in Food Management and Culinary Arts-, Culture Science \& Hospitality Research, (2013), Vol.19, No.2, pp.76-92, DOI : 10.20878/cshr.2013.19.2.007

[6] J. Y. Do, The Effect of Major Satisfaction and Faculty-Student Interaction of University Students Majoring Dance on Their School Life, Official Journal of the Koeran Society of Dance Science, (2017), Vol.34, No.4, pp.69-82, http://dx.doi.org/10.21539/ksds.2017.34.4.69

[7] S. K. Park, H. S. Lee, The Effect of Perceived Work Values of University Students' on Major Satisfaction and Major Commitment: Focused on University Students of the Hotel Tourism Management Department, Northeast Asia Tourism Research, (2016), Vol.12, No.1, pp.219-235, UCI : G704-SER000010265.2016.12.1.008

[8] J. L. Holland, J. E. Holland, Vocational in decision: More evidence and speculation, Journal of Counseling Psychology, (1977), Vol.24, No.5, pp.404-414, https://doi.org/10.1037/0022-0167.24.5.404

[9] J. S. Jang, The Relationships among Career Identity Status, Parental Attachment and Psychological Separation of College Students, Yonsei University, Master's Thesis, (2013)

[10] J. S. Kim, The effect of career self-efficacy and career resilience on career identity and career decision level, The Journal of Learner-Centered Curriculum and Instruction, (2019), Vol.19, No.9, pp.99-118, DOI : 10.22251/jlcci.2019.19.9.99 